\title{
Ignacio Manuel Altamirano, Clemencia y la ecocrítica.
}

Ignacio Manuel Altamirano, Clemencia and the ecocritic.

DOI: $10.32870 /$ sincronia.axxv.n79.10a21

\author{
Mariana Guadalupe Bueno Ibarra \\ Universidad de Guadalajara (MÉXICO)
}

CE: marian.buenoib@gmail.com / ID ORCID: 0000-0001-5732-9817

\section{Esta obra está bajo una Licencia Creative Commons Atribución-NoComercial 4.0 Internacional}

Recibido: $30 / 03 / 2020$

Revisado: $18 / 10 / 2020$

Aprobado: 05/11/2020

\section{RESUMEN}

La narrativa de Ignacio Manuel Altamirano ha sido uno de los testimonios más notables de la literatura mexicana del siglo XIX, por lo que su estudio sugiere diversas vías de acercamiento a uno de los momentos históricos más importantes de la vida cultural de México. El presente trabajo analiza desde la perspectiva de la teoría ecocrítica la importancia fundamental del espacio y la naturaleza en la literatura. Al ser Clemencia una novela inscrita dentro del romanticismo, lo natural se conforma dentro de un espacio abierto con notables descripciones acerca de las montañas, plantas y jardines.

La ecocrítica sienta su estudio desde la perspectiva de la naturaleza y el cómo se vuelve parte activa en la narración; da testimonio de una época concreta en donde se revela la relación humana / no-humano. Es en Clemencia donde estas características funcionan dentro de un espacio, en el cual el mundo natural posee gran importancia, un escenario poético, natural, conformado por el paisaje decimonónico de la ciudad de Guadalajara.

Palabras Clave: Naturaleza. Espacio. Paisaje. Literatura. Ecología. Medio ambiente.

\section{ABSTRACT}

Ignacio Manuel Altamirano's narrative has been one of the testimonies more remarkable of Mexican literature of the XIX century. Its study suggests many ways of approach to one of the more important historic and cultural time living in Mexico. The actual work analyses from the perspective of the ecocritic theory the fundamental importance of space and 
nature in literature. Clemencia is a novel that inscribes in the romanticism, nature develop in an open space with notables descriptions about mountains, plants, and gardens.

The Ecocritics based its study in a natural perspective and about how it comes an active part in the narration; it gives a testimony of a concrete époque and reveals the relation between human / no-human. It is in Clemencia where this characteristic works in a space, where the natural world has and gives transcendental importance, a poetic scenery, nature, conforms for the nineteenth landscape in Guadalajara city.

Keywords: Nature. Space. Landscpae. Literature. Ecology. Enviroment.

\section{Introducción}

El estudio del espacio narrativo brinda diversas posibilidades de acercamiento: desde los estudios filosóficos tradicionales, hasta la propuesta de Gastón Bachelard sobre el espacio poético.

La tradición filosófica sigue líneas particulares de pensamiento. Para Platón, el espacio se refiere únicamente a un receptáculo: lo que puede llenarse. Lo trata mediante el mundo de las ideas. En cambio, Aristóteles concibe al espacio como lugar; su tratamiento parte del espacio físico. El espacio es visual y en él se encuentra inmerso el ser. De esta forma es como introduce el concepto de ser dentro de la espacialidad; es material, pues existe en el tiempo y espacio. A su vez, Heidegger en su obra El ser y el tiempo, aborda el tema desde una ontología fundamental que estudia al ser. De ello se deriva el Dasein; es la relación recíproca del hombre y el ser, "es a partir de esta estructura analítica del Dasein, que relaciona al hombre con el ser, con el mundo y el tiempo, que se da la comprensión del espacio en la estructura del Dasein" (Gómez, 2016, p.5). El sentido y la búsqueda del mismo, parten del análisis propio del hombre, quien es un ser que se interroga sobre su propia existencia.

Por su parte, Gastón Bachelard (2000) aborda el espacio a partir de la imagen poética en donde busca la determinación fenomenológica de las imágenes; la imagen emerge al ser desde su condición visible. Su estudio abarca los valores de intimidad del espacio, en donde menciona: “Porque la casa es nuestro rincón del mundo [...] todo espacio realmente habitado lleva como 
esencia la noción de casa” (p.28). De esta manera, continúa con la tradición filosófica propuesta por Aristóteles y Heidegger desde la perspectiva poética.

Las observaciones se amplían en extensión y complejidad, se establece el cimiento de elementos espaciales. Brevemente se hace mención de ello, como una forma de mostrar los antecedentes del estudio del espacio, la fenomenología. Sin embargo, para los motivos de la presente investigación, el enfoque se centra en el campo de la ecocrítica, la cual también se encarga del estudio del espacio, pero a un nivel de unión humana con la naturaleza. La teoría ecocrítica fundamenta este estudio de los elementos espaciales de la narrativa de Clemencia.

\section{El espacio: una revisión desde la ecocrítica}

Clemencia da una muestra significativa de la importancia que Altamirano concede al espacio, y si se entiende a partir de la concepción aristotélica de que el espacio es un contenedor, algo físico, saca a la luz los elementos constitutivos percibidos por la vista. La naturaleza se descubre como parte fundamental, activa en el exterior e interior de la vida humana. El paisaje natural se manifiesta con determinación en los protagonistas, y a su vez los define en su entorno como parte de la influencia. La aplicación del análisis ecocrítico demuestra, desde la perspectiva de la naturaleza, el espacio narrativo de la novela.

La ecocrítica estudia la relación entre la naturaleza y la literatura, la cual se desarrolla en una conciencia ecológica establecida por el enlace con el medio ambiente físico. El espacio se vuelve un campo de vinculación entre todos los seres vivos, las relaciones son partes determinantes que se representan en los textos, en los escritores, en el mundo. Tales representaciones dejan ver el contacto; la convivencia se sujeta a una coexistencia, la cual se representa en la literatura bajo formas contextuales e históricas sobre procesos, denuncias y modos de vida. La premisa en la cual se desenvuelve el punto central de la ecocrítica es la siguiente:

La ecocrítica, pues, toma como punto central el análisis de la representación de la naturaleza y las relaciones interdependientes de los seres humanos y no-humanos según han quedado reflejados en las obras de la cultura y de la literatura (Flys et al., 2010, p.18). 
Tal interdependencia entre el mundo físico y la cultura humana se observa a partir de una afectación y un impacto mutuos. El entorno físico en la literatura se observa como un agente activo, pues recala directamente en el mundo narrativo. De esta manera es como los protagonistas y personajes en general se ven involucrados entre ellos y lo que no es humano: flores, animales, paisaje, naturaleza. Hay una clara relación entre lugar e identidad.

La ecocrítica ${ }^{1}$ surge en la década de 1990 . Sus fundadores pertenecían a la asociación de literatura del oeste americano. Parte del proceso que les llevó a formar esta rama teórica literaria, se refiere a la observación del impacto del paisaje en la vida de los habitantes, como una parte integral del desarrollo cultural. Flys, Marrero y Barella (2010), manifiestan que el texto canónico que inaugura los estudios ecocríticos es la introducción de la antología de The Ecocriticism Reader escrita por Cheryll Glotfelty (1996), quien en su texto examina los orígenes de la palabra ecocrítica:

The term ecocriticism was possibly first coined in 1978 by William Rueckert in his essay "Literature and Ecology: An Experiment in Ecocriticism". By ecocriticism Rueckert meant "the application of ecology and ecological concepts to the study of literature". Rueckert's definition, concerned specifically with the science of ecology, is more restrictive than the one proposed in this anthology, which includes all possible relations between literature and the physical world.

[El término de ecocrítica posiblemente fue mencionado por primera vez en 1978 por William Rueckert en su ensayo "Literatura y Ecología: un experimento en la ecocrítica". Por ecocrítica Rueckert quiere decir "la aplicación de la ecología, así como conceptos ecológicos para el estudio de la literatura". La definición de Rueckert, encaminada específicamente con la ciencia de la ecología, es más restrictiva que la propuesta en esta antología, la cual incluye todas las posibles relaciones entre la literatura y el mundo físico] ${ }^{2}$ (pp.19-20).

\footnotetext{
${ }^{1}$ La ecocrítica, de acuerdo con Carmen Flys, José Manuel Marrero y Julia Barella (2010), es una nueva escuela de crítica literaria de origen norteamericano, que ha trascendido a otros países. La Universidad de Alcalá, España, cuenta con un proyecto de investigación que busca la divulgación, el interés y el desarrollo teórico de la escuela.

${ }^{2}$ Traducción mía.
} 
Los inicios de la ecocrítica responden al llamado de una crisis global en la cual se toman en cuenta los cambios naturales, como lo demuestra Rueckert ${ }^{3}$ en su definición, pero Glotfelty ve en ello un punto de partida necesario entre la literatura y el mundo físico, natural. De tal manera, sobre estas premisas fundacionales, la ecocrítica se muestra como una escuela crítica literaria de amplio campo de acción entre literatura y naturaleza. Carmen Flys (2010) en su artículo "Literatura, crítica y justicia medioambiental", ahonda más sobre su origen:

La ecocrítica surgió a partir del interés por el género literario de la nature writing (literatura de la naturaleza), una serie de ensayos literarios sobre la naturaleza, próximo movimiento ecologista y en pro de la conservación de la naturaleza y su disfrute. La ecocrítica se definió como el estudio de las relaciones humanas con su entorno según están reflejadas en la literatura (p.84).

El análisis literario se centra en el lugar y la naturaleza, con el objetivo de hacer visible la serie de problemáticas actuales con el entorno, así como la imposibilidad de observar el distanciamiento entre seres humanos y naturaleza; varía de acuerdo con la región. De tal manera Flys (2010) -junto a Marrero y Barella- abordan a uno de los críticos más relevantes del movimiento, Lawrence Buell, el cual distingue dos oleadas históricas en la ecocrítica:

En la primera, el interés primordial se centró en la preservación de la naturaleza y en la exaltación de su belleza. Muchos de sus iniciadores rechazaban que la crítica y la teoría literaria estuvieran subidas a una torre de marfil, y procuraban acercarlas al mundo real (p.16).

Una de las características principales de la ecocrítica y que permea en la actualidad, es la preservación; el activismo ecológico, del cual derivan las reflexiones pertinentes de acuerdo con el análisis literario. En esta primera oleada, primaba la experiencia sobre la teoría e incluso se debatía

\footnotetext{
${ }^{3}$ Flys, Marrero y Barella (2010), localizan a su vez una fuente diferente respecto al término: "El nombre de ecocriticism (ecocrítica) fue acuñado por William Howarth en su ensayo, 'Some Principles of Ecocriticism', que data de la década de 1970 " (p.17). Los orígenes de la palabra son mencionados por ambos autores.
} 
si debía personalizarse al grado de incluir vivencias propias en el ensayo académico. La necesidad de alejarse de la rigurosidad académica fue uno de los puntos más importantes, pues suponía limitaciones dentro del campo de estudio. La segunda oleada trajo consigo nuevos debates y cuestionamientos respecto a la visión de la naturaleza de la primera; los debates se centraban en su estado ya no como puro e intacto, sino como una fuente de contacto directo en la sociedad. Esto traía consigo la inclusión de nuevos géneros literarios, así como variadas perspectivas:

Esta oleada se caracteriza por la consolidación de tendencias como las de la ecofeminismo ${ }^{4}$ y la justicia medioambiental, sin que por ello la primera tendencia haya sido abandonada. Como Lawrence Buell ya señaló, la ecocrítica, hoy por hoy, no ha seguido ninguna revolución en cuanto a metodología, ni ha aportado un paradigma definitivo, aunque el debate sigue abierto (pp.19-20).

Las tendencias siguen de igual manera el mismo eje central de la ecocrítica: se enfocan en la tierra. Respecto a la falta de una revolución metodológica, existe una pauta clara y repetitiva dentro de los estudios: la interdisciplinariedad. Hay un deseo general de inclusión de diversas ramas en las cuales se busca el diálogo para fungir activamente como agentes de cambios en una honda visión espacial ecológica. Dejar el debate abierto equivale a la elaboración de nuevas propuestas por parte de académicos estudiosos del tema, con ello la inclusión de voces y diversas realidades sociales que responden a las tendencias y necesidades de la actualidad. La revolución podría encontrarse con la oportunidad de diálogo entre sociedad, literatura y naturaleza.

El objetivo principal apunta a la recuperación de la conciencia sobre el espacio. La presente investigación sigue líneas de análisis ecocríticas, como la búsqueda y la observación del espacio en la novela. Flys (2010) explica la relación entre el texto y la naturaleza:

\footnotetext{
${ }^{4}$ De acuerdo con el glosario básico bilingüe propuesto por Carmen Valero y Carmen Flys en la antología Ecocríticas, el término ecofeminismo (ecofeminism) se define como: "1. m. Corriente de pensamiento aparecida en Europa en el último tercio del siglo XX que estudia las relaciones entre la mujer y la naturaleza desde muy diversas perspectivas" (Valero y Flys, 2010, p.373). En cuanto a la diversidad de términos especializados usados en la ecocrítica, se revisarán aquellos relacionados con el análisis de Clemencia en el segundo apartado del capítulo.
} 
La literatura siempre ha sido una representación, sea de la vida o de las actitudes culturales de un pueblo [...] Así pues, el texto refleja las creencias y valores del autor, pero la reacción del lector que intenta valorar el mensaje del texto también revela su propia forma de vivir en el mundo. De hecho, a través del estudio de la literatura de una época o pueblo, se puede llegar a conocer cuáles son sus valores (incluyendo los relacionados con el medio ambiente). (pp.106-107).

Tal muestra relacional se ve afianzada con las palabras de la investigadora Julia Barella (2010), quien en su artículo5: "Naturaleza y paisaje en la literatura española", continúa con la idea principal de Flys:

Vamos a considerar, en este trabajo, que la ecocrítica incorpora un enfoque enriquecedor a la hora de revisar algunas de nuestras obras literarias, si atendemos a la relación del escritor, de sus personajes y/o sus metáforas con el medio ambiente. (p.219).

Una de las cuestiones que resaltan de su argumento es la sentencia: "en este trabajo", lo cual deja ver la presencia de adecuaciones pertinentes de acuerdo con el tema de investigación.

Mientras algunos estudios se centran en la justicia medioambiental ${ }^{6}$, otros indagan en los diversos aspectos que brinda la literatura como testimonio. Se busca en ella la representación de la naturaleza, así como los elementos del espacio y su significancia en la narración; cada estudio se ajusta a los conceptos de sus objetivos ${ }^{7}$. Las ecocríticas se ligan a intenciones únicas, continúa Barella (2010) con su reflexión:

La ecocrítica se ha convertido en un movimiento interdisciplinar que agrupa a investigadores del mundo del arte, de la literatura, de la filosofía, la biología, la sociología y la antropología (Lastra); a todos ellos aporta interesantes puntos de vista para abordar las

\footnotetext{
${ }^{5}$ El artículo se encuentra en la antología Ecocríticas.

${ }^{6}$ De acuerdo con Flys (2010): "Los textos de justicia medioambiental son mayoritariamente escritos por personas pertenecientes a grupos minoritarios, sean raciales, étnicos, sexuales o culturales" (p.109).

${ }^{7}$ Se hace hincapié en este punto con el objetivo de alumbrar aún más los detalles únicos que se desenvuelven en los estudios ecocríticos, ya que su flexibilidad es una característica para revisar.
} 
relaciones del ser humano con la naturaleza, con el medio ambiente y con el mundo que le rodea (p.219).

La agrupación de diversas ramas se presta como una conexión necesaria para el conocimiento, en donde lo fundamental viene a ser la concepción del espacio; entendimiento con la naturaleza. El lugar tiene un impacto trascendental en la vida humana, cada parte del espacio se llena con cada una de las partículas de tal vida, así como la no-humana. La esencia del hombre reside en la naturaleza; se trasluce en las obras literarias de cada época.

\section{Altamirano y la ecocrítica}

Mientras en la actualidad surge una crisis de talla mundial, debido a la incapacidad de convivencia con la naturaleza que parte de una negación hacia la misma, en el siglo XIX en México, una de las inquietudes del mundo intelectual-cultural tenía que ver con la síntesis de identidad nacional, por lo que al observar a la naturaleza la dotan de aceptación y valoración.

La actitud cultural para los escritores del siglo XIX se basaba en la necesaria nacionalización de las perspectivas. Tras las turbulentas guerras que azotaron al país, fue menester el sentimiento exaltado hacia la patria. El escritor Ignacio Manuel Altamirano destaca la necesidad de integración mexicana. Forjado en el romanticismo, se corresponde con sus características, las cuales son: el descubrimiento del hombre en sí mismo; la concepción del espacio exterior como una extensión de él; la naturaleza se presenta a través del paisaje; la realidad natural es el entorno ideal de contemplación y reflexión, se encuentra el hombre en armonía con su espíritu. Tal inscripción del hombre decimonónico trae a cuenta sucesos presentes, que Barella (2010) explica mediante la ecocrítica:

Fenómenos como la deforestación, con la consiguiente desertización, la desaparición de especies animales o la contaminación de las aguas son algunas de las consecuencias de los excesos urbanísticos [...] Estos hechos están modificando sustancialmente una naturaleza y un paisaje sobre los que se ha ido construyendo a lo largo de la historia la memoria de sus 
habitantes y su identidad cultural. Desde la ecocrítica, podemos ver cómo se ha ido construyendo ese paisaje cultural a través de nuestros textos literarios, descifrar sus cualidades estéticas y reconocer su historia (p.220).

La construcción del paisaje cultural en el México del siglo XIX responde a una construcción de identidad, en la cual, cada ciudadano enfrenta una condición general geográfica irrevocable. El pensamiento de Altamirano da cuenta de ello. En Carta a una poetisa (1872) publicada por partes el, 3, 10, 31 de marzo y 7 de abril de 1872, manifiesta argumentos respecto a la elaboración de la poesía; su discurso se centra en tomar los elementos nacionales, observar e inspirarse en el entorno:

Así, no tendrá que ir a buscar en los viajeros de Tierra Santa, como Chateaubriand y Lamartine, la descripción de Jerusalén (que usted no conoce), para formar su cuadro, sino que le bastará asomarse a su ventana o recorrer los campos en derredor de esa linda población tropical en que afortunadamente reside, para darnos en sus composiciones, bellísimos cuadros de la naturaleza americana, capaces por sí solos de encantar a los amantes de la verdadera poesía, que es la poesía nacional (p.47).

Se encomienda a la naturaleza americana como raíz de la nación y encarece dejar de lado la utilización de los modelos extranjeros, pues el espacio responde a realidades particulares. Retoma la naturaleza como punto central dentro de sus recomendaciones poético-estéticas:

De todos los peligros que ella y otras han corrido, puede usted librarse con sólo buscar la inspiración en la naturaleza. No hay arte poética igual a la que ella nos ofrece con su elocuente verdad. Estudiándola, comprenderá usted que, aunque en la poesía erótica es muy difícil ser original, al menos puede salirse del sendero trillado [...] (p.68).

El contacto divino, poético, entre Dios y la humanidad reside en la naturaleza. La constante entre tales visiones, evoca una relación de dirección creativa. Insiste en encontrar la respuesta en el 
entorno mismo de la poesía, el cual responde a un paisaje en común. A lo largo de la carta destaca entre sus "consejos literarios", la palabra verdad; la "elocuente verdad" que la naturaleza brinda.

Para Altamirano, la naturaleza se muestra a favor de la estética, lo cual deriva en un método de inspiración por parte del artista, pues se trata de la producción de bellas imágenes. Sin embargo, también se encuentra en ella a Dios y a la verdad. La representación de tal verdad responde a la necesaria misión de Ignacio Manuel Altamirano en la construcción de la nación.

En sus crónicas deja también el autor de Clemencia testimonio sobre su relación con la naturaleza y el espacio: el 20 de marzo de 1870 escribe: "Yo comprendo muy bien que, para algunos, como para mí (lo confieso sinceramente) el lugar es algo que vive y que habla, algo que entra por mucho en nuestros efectos y que influye poderosamente en el corazón" (1870, p.131). La concepción del espacio, para Altamirano, se vuelve un asunto central dentro de su pensamiento; se trata de una honda comprensión que abriga la interdependencia. El lugar se mueve y actúa en conjunto con el hombre.

El espacio confiere los elementos de apreciación, lo cual deriva en una profunda contemplación; asentamiento espiritual que influye en las actividades humanas. Barella (2010), quien a su vez cita a Rafael Argullol (2006), concluye que el espacio se vuelve más que un marco:

Como asegura Rafael Argullol en su reflexión sobre el paisaje romántico, la escisión entre hombre y entorno natural se produce de manera irreversible; desde entonces, el hombre se sentirá fascinado ante la inmensidad de la naturaleza que le rodea y que contempla, pero, al mismo tiempo, se sentirá expulsado de ella. La soledad y la melancolía del contemplador romántico se enfrenta a un paisaje que "ya no es un mero marco físico sino un espacio profundo, esencia". (p.226).

La escisión del hombre del romanticismo es irremediable; surge como una apropiación del espacio en la cual se visibiliza la individualización del hombre y los lazos con la tierra; se adecua a la empresa nacionalista, característica de los románticos. Altamirano lo demuestra con claridad en 
otro de los pasajes de sus crónicas8: la Correspondencia entre Próspero y el Nigromante (1868), fechada en Colima el 20 de febrero de 1864. En la carta deja ver sus impresiones sobre el mar:

El cielo tiene allí una belleza terrible; las aguas con sus insondables abismos parecen mirarnos con lástima. Entonces se quiere más la vida porque se la siente más débil y más miserable. A mí no me vino el orgullo de verme dominando aquel terrible elemento, ni sentí, como sienten otros, la superioridad del hombre, rey de la creación. Confieso a usted que, al verme en aquel pequeño y viejo buquecillo, manejado por cinco marineros, y entregado a merced de las olas que abrían en derredor nuestro, pavorosas profundidades, lejos del amparo de los hombres y confiando sólo en la grandeza de Dios, me creí humillado y me vinieron deseos de arrodillarme al sentir que soplaba en mis cabellos salvajes y en mi frente, algo desconocido y terrible como el aliento del Eterno [...] (p.113).

Tal como Barella lo manifestó a través de su cita a Argullol, se trata de la existencia de un espectador romántico que se enfrenta a la naturaleza; tal contemplación le hace internarse en un espacio profundo, una esencia. La característica fundamental finalmente se hace vista, ejerce tal atracción que afecta el espíritu. Altamirano tiene un alto entendimiento de lo que surge tras la contemplación de su entorno; la influencia en sí mismo. Flys mencionaba cómo la ecocrítica permitía visibilizar al autor y su relación con el espacio a fin de obtener conocimiento respecto a las diversas miradas con las cuales se ve al pasado. La comprensión del autor y sus metáforas en la narración, el espacio como el elemento integrante. En la crónica “Chapultepec" (1875), fechada el 2 de agosto de 1875, el escritor manifiesta un alto grado de afinidad con la existencia de un bosque en medio de la ciudad:

El más hermoso sin duda de todo el valle de México. La naturaleza ha reunido aquí todos sus encantos para dar atractivo al lugar. Estos árboles colosales y majestuosos que formando un bosque sombrío circuyen con una enorme guirnalda la colina, que semejante a una

\footnotetext{
${ }^{8}$ En general se observa cómo en sus crónicas pinta cuadros de costumbres, el sentimiento nacional se encuentra activo en Altamirano; observa las necesidades del pueblo. Es en la naturaleza donde observa a la nación en su máxima extensión y se recrea en ella. A través de las descripciones del espacio se puede tener conocimiento sobre el impacto del paisaje en Altamirano.
} 
fortaleza vela cerca de la gran ciudad [...] la suavidad del aire embalsamado con el aroma de las plantas y de las flores, todo debe hacer de Chapultepec el asilo predilecto de los mexicanos [...] (p.159).

La naturaleza para el autor de Clemencia conlleva cinco elementos esenciales: la unidad nacional; el contacto divino; la inspiración estética, la verdad y el refugio de la vida urbana. En los cinco puntos la influencia se toma como punto de partida general de la relación entre el contacto humano / nohumano. Mediante la revisión de sus cartas y crónicas, se observa cómo la relación de Altamirano con el entorno genera en él un vínculo vital.

Al estudiar el espacio narrativo, se toman en cuenta las formas únicas que van apegadas con la incorporación de elementos activos en los sucesos de la historia. El hecho de encontrar numerosas alusiones a las flores, árboles y palmas en Clemencia, los vuelve componentes de la naturaleza esenciales en la trama pues ejercen actividad en sus vidas, más allá de la presencia; la ecocrítica mira tales muestras como procesos culturales. Se vuelve evidente la sensibilidad hacia el espacio natural. Glotfelty (1996) se encarga de describir los cuestionamientos en común que comparten los ecocríticos, a favor de inquietudes similares:

Ecocritics and theorists ask questions like the following: How is nature represented in this sonnet? What role does the physical setting play in the plot of this novel? Are the values expressed in this play consistent with ecological wisdom? How do our metaphors of the land influence the way we treat it?

[Ecocríticos y teóricos se preguntan cuestiones como las siguientes: ¿Cómo la naturaleza se representa en este soneto? ¿qué rol juega el escenario físico en la trama de esta novela?, ¿los valores expresados en la obra traen consigo sabiduría ecológica?, ¿cómo nuestras metáforas de la tierra influencian la manera en que la tratamos?] ${ }^{9}$ (pp.18-19).

El espacio se vislumbra como el centro de las problemáticas; la relación de los personajes y la utilización de sus espacios aparecen sobre un discurso respecto a la naturaleza. Sin embargo, más

\footnotetext{
${ }^{9}$ (Traducción mía).
} 
adelante Glotfelty (1996) incluye cuestiones a lo que hoy se consideran parte de las tendencias teóricas de la ecocrítica:

How can we characterize nature writing as a genre? In addition to race, class, and gender, should place become a new critical category? Do men write about nature differently than women do? In what ways has literacy itself affected humankind's relationship to the natural world? How has the concept of wilderness changed over time?

[¿Cómo podemos establecer la escritura de la naturaleza como un género? Adicionalmente a la raza, clase, y género, ¿el lugar debería considerarse como una nueva categoría crítica?, ¿los hombres escriben acerca de la naturaleza diferente a como las mujeres lo hacen?, ¿de qué maneras el conocimiento en sí mismo ha afectado a la humanidad y su relación con el mundo natural?, ¿cómo el concepto de la naturaleza cambia de acuerdo con el tiempo?] ${ }^{10}$ (p.19).

Los cuestionamientos persiguen un fin estrechamente relacionado con los lazos sociales y los lazos con el mundo natural que parece tan lejano; se traduce en la convivencia de todos en el espacio. Hay una concentración de dudas respecto al camino que ha seguido la humanidad en conjunto con la naturaleza, sobre todo la actitud cultural que ha permeado en el hombre. Más adelante Glotfelty (1996) trae a colación las diferencias entre la teoría literaria general y la ecocrítica de la siguiente forma:

Literary theory, in general, examines the relations between writers, texts, and the world. In most literary theory "the world" is synonymous with society - the social sphere. Ecocriticism expands the notion of "the world" to include the entire ecosphere. If we agree with Barry Commoner's first law ecology, "Everything is connected to everything else", we must conclude that literature does not float above the material world in some aesthetic ether, but, rather, plays a part in an immensely complex global system, in which energy, matter, and ideas interact.

${ }^{10}$ (Traducción mía). 
[La teoría literaria, en general, examina la relación entre escritores, textos, y el mundo. En la mayor parte de la teoría literaria "el mundo" es sinónimo de sociedad -esfera social. La ecocrítica expande la noción de "el mundo" para incluir a la ecosfera entera. Si estamos de acuerdo con la primera ley de ecología de Barry Commoner, "Todo está conectado con todo lo demás", debemos concluir que la literatura no se encuentra sobre el mundo material en un poco de éter estético, sino que más bien juega una parte dentro de un inmenso y complejo sistema global, en el cual la energía, la materia e ideas interactúan]. ${ }^{11}$ (p. 19).

El espacio narrativo se conforma de igual manera para el mundo de los personajes que para el mundo natural. Glotfelty señala el vínculo entre todo lo que contiene el espacio, ya lo diría Bachelard (2000): "El espacio concentra ser en el interior" (p.22). Asimismo, tal concentración posibilita la convivencia a un nivel de íntimo valor. Por su parte, la teoría ecocrítica considera a todos los elementos que se conforman en el espacio, como esfera natural.

Frederick Turner (1996) en su artículo "Cultivating the American Garden" publicado en The Ecocriticism Reader, lo plantea de la siguiente manera: "We are natura naturans, nature naturing" (p.42). Más allá de lo bueno, correcto o hermoso, la naturaleza vive con nosotros, es el espacio que se revela bajo una forma de unión; un sentido que dota de acción. Al develar la noción significativa de lo que implica verdaderamente la palabra naturaleza, Turner aclara lo siguiente a este respecto:

Most of us, asked what nature is, would probably make a vague gesture toward the nearest patch of Green vegetation and say, to begin with, something like "Well, it's what's out there, not what's in here." [...] Nature bears the weight of our activities, but in the long run renews itself and remains just as it was [...] Nature, according to science, is as much "in here" as it is "out there"

[La mayoría de nosotros, al preguntarse qué es la naturaleza, probablemente con un vago gesto señale el prado verde más cercano y diga algo así como: "Bueno, es lo que está ahí, no lo que está aquí." La naturaleza soporta el peso de nuestras actividades, pero a la

\footnotetext{
${ }^{11}$ (Traducción mía).
} 
larga se renueva a sí misma y permanece como era [...] La naturaleza, acorde con la ciencia, es tanto lo que "hay allá" como lo que "hay aquí]. ${ }^{12}$ (p.42).

La naturaleza se manifiesta en todo lo que rodea a los seres vivos. Es el soporte de las actividades humanas, se visibiliza tanto en el espacio interior como en el exterior. Existen escenarios dentro de Clemencia en los cuales se puede percibir con claridad a ambos: "lo que hay aquí", así como "lo que hay allá". El siguiente pasaje corresponde a los primeros momentos de contacto con el lugar natural. Según la propuesta de Turner, se describe el espacio de afuera, el exterior:

Efectivamente, la llanura que rodea a la ciudad da un aspecto extraño al paisaje, que no se observa al aproximarse a ninguna de las otras ciudades de la República. En las mañanas del estío, o en los días del otoño y del invierno, como en los que llegué por primera vez a Guadalajara, aquel valle es triste y severo; el cielo se presenta radioso y uniforme, pero el sol abrasa y parece derramar sobre la tierra sedienta torrentes de fuego (Altamirano, 2016, p.15).

Por otra parte, la descripción de la casa de Isabel corresponde a "lo que hay aquí", espacio interior:

Los dos jóvenes atravesaron alegremente los umbrales de la linda casita, luego un pequeño patio que parecía una gruta de verdura y de flores con un risueño surtidor de mármol, y bajo una cortina de enredaderas penetraron en el corredor y se detuvieron en la puerta de la antesala (p.23-24).

En los pasajes anteriormente descritos, ambos espacios se corresponden de igual manera y se vuelve visible la presencia natural en cada uno de ellos. Por un lado, se encuentra la descripción del paisaje; Ilanura y valle de Guadalajara. El exterior ubica e informa sobre el proceso de observación por parte del narrador. En cambio, la casa de Isabel describe el espacio de un interior, en el cual es posible observar cómo se refuerza el vínculo con la naturaleza; realmente cuando habla de lo que hay "aquí" como "allá" alude a la realización de una relación inseparable.

\footnotetext{
${ }^{12}$ (Traducción mía).
} 
El espacio narrativo tiene como objetivo hacer clara la interdependencia entre lo humano y lo no-humano. El narrador es capaz de observar, tal como lo menciona Aristóteles (2011): "la vista mejor que los otros sentidos, nos da a conocer los objetos y nos descubre entre ellos gran número de diferencias" (p.5). Sin embargo, más que las diferencias, permite establecer una pauta en la relación con la naturaleza. Los puntos de común encuentro con la cotidianidad.

Clemencia es una remembranza de aquella naturaleza de grandes extensiones; cuando aún el área urbana conformaba una limitada parte del territorio. Es un testimonio que deja ver las preocupaciones románticas de Ignacio Manuel Altamirano, quien en su estrecha conexión con el espacio hace alusión a la atmósfera del momento. El clima se presenta como una parte primaria dentro de la contextualización espacial.

La época del año en la cual transcurre la introducción de la historia sugiere un clima muy específico: "Una noche de diciembre" (Altamirano, 2016, p.3). El clima, a su vez, alienta el estado del ánimo de los individuos presentes en la velada. Asimismo, penetra en el espacio interior como una especie de inundación por parte del clima exterior. Y continúa:

[...] mientras que el viento penetrante del invierno, acompañado de una lluvia menuda y glacial, ahuyentaba de las calles a los paseantes, varios amigos del doctor L.... tomábamos el té, cómodamente abrigados en una pieza confortable de su linda, aunque modesta casa (p.3).

La interacción primaria con la naturaleza se ubica en esta primera parte, con el clima; no es más que el establecimiento del diálogo entre los personajes y el espacio. Será un punto clave dentro de la historia, ya que, el acercamiento a considerar las cuestiones climáticas se determina como una constante a la hora de manifestar ciertos escenarios en los cuales se desenvuelven los personajes.

La manifestación de la época de año se encuentra en diversos pasajes. El capítulo dos, por ejemplo, lleva por nombre "El mes de diciembre de 1863". Ahí se alude a las situaciones climáticas provenientes de la época, es visible la incidencia del invierno. Las siguientes líneas expresan su continuidad: 
- "[...] mientras que el viento penetrante del invierno [...]" (p.3).

- "Aunque el invierno aquí no es nada riguroso como usted lo conoce [...]" (p.59).

- "Después de la Navidad estaban la guerra, las montañas, las privaciones, la derrota, tal vez la muerte" (p.75).

- "El invierno con sus galas de nieve, con sus pinos y sus musgos (lo cual es una exageración en Guadalajara, donde casi no hay invierno) [...]" (p.76).

- "Era el 5 de enero de 1864, y ya avanzada la noche, que estaba fría y nebulosa" (p.83).

La condición invernal se interpreta como la anticipación de los sucesos. Hay una conexión entre el clima y los acontecimientos a lo largo de la historia; se percibe una melancolía de índole amorosa. Las experiencias provenientes de los meses determinan el principio de un fin; el invierno es un momento decisivo en la vida de los personajes. En el capítulo 23: "La última Navidad", sucede la promesa de duelo entre Fernando Valle y Enrique Flores. Se convierte en el suceso culminante entre ambos pues supone una ruptura.

[...] vuelvo a tomar el hilo de mi narración, por lo cual retrocederé hasta los últimos de diciembre de 1863, época en que todo el mundo en Guadalajara hacía ya sus aprestos, ora para salir también de la ciudad con el gobernador republicano, ora para recibir a los invasores (p.75).

El clima activa ciertos sentimientos sobre la trama; el invierno no es más que una anticipación de un término, el fin de la vida como la conocieron hasta ese punto los personajes y el narrador. El invierno envuelve a los habitantes del espacio exterior, pero influye de manera terminante en los eventos humanos.

Altamirano dedica tres capítulos, exclusivamente, a la descripción de la naturaleza: "Llegada a Guadalajara" (5); "Guadalajara de lejos" (6) y "Guadalajara de cerca" (7). En ellos se refleja la necesidad de hacer visibles los paisajes nacionales. Son capítulos cortos que se encargan de enunciar el espacio, la tierra. La intención de Altamirano (2016) es justificada en el siguiente pasaje: "Perdonen ustedes mi afición a describir, y no la juzguen tan censurable mientras que ella sirva para 
dar a conocer las bellezas de la patria, tan ignoradas todavía" (p.17). A través de la voz del narrador, se informa sobre la necesidad de difundir la existencia de los lugares naturales de la nación; todo ello se establece como una extensión más de las condiciones espaciales anteriormente establecidas. Es una parte esencial dentro del espacio narrativo.

\section{A manera de conclusión...}

En Clemencia se puede encontrar un diálogo intenso entre naturaleza y personajes; sin embargo, en los capítulos dedicados a la descripción se encuentra particularmente una imagen detallada de la ciudad de Guadalajara. Contemplar la disposición del espacio del siglo XIX es traer a colación lo que Barella mencionaba acerca de cómo con la ecocrítica es posible observar el cómo ha sido construido el paisaje cultural a través de los tiempos.

La física del espacio, el cómo el hombre se relaciona y se asienta mediante la serie de relaciones que teje con el mundo, revelan una identificación en la cual se asientan una relación encaminada al lugar y cómo éste contribuye a la construcción de identidad humana. Dota de significado a la búsqueda de sentido, que para Altamirano no es otra que la identificación nacional.

\section{Referencias}

Altamirano, I. (1868). Correspondencia entre Próspero y el Nigromante. Ignacio Manuel Altamirano VII. Crónicas, tomo I. (pp.106-157) México: SEP.

Altamirano, I. (1870). 20 de marzo de 1870. Ignacio Manuel Altamirano VIII. Crónicas, tomo II. (pp.130-165) México: SEP.

Altamirano, I. (1872). Carta a una poetisa. Ignacio Manuel Altamirano XIII. Escritos de literatura y arte, tomo II. (pp.42-69) México: SEP.

Altamirano, I. (1875). Chapultepec. Ignacio Manuel Altamirano IX. Crónicas, tomo III. (pp.159-161) México: SEP.

Aristóteles. (2011). Metafísica. Porrúa: México.

Bachelard, G. (2000). La poética del espacio. Fondo de Cultura Económica. Argentina: Buenos Aires. 
Barella, J. (2010). Naturaleza y paisaje en la literatura española. Ecocríticas/Literatura y medio ambiente. (pp.219-238) Madrid: Iberoamericana/Vervuert.

Flys, C. (2010). Literatura, crítica y justicia medioambiental. Ecocríticas/Literatura y medio ambiente. (pp.85-119) Madrid: Iberoamericana/Vervuert.

Flys, C., Marrero, J., Barella, J. (2010). Ecocríticas: el lugar y la naturaleza como categorías de análisis literario. Ecocríticas/Literatura y medio ambiente. (pp.15-25) Madrid: Iberoamericana/Vervuert.

Glotfelty, C. (1996). Introduction. The Ecocriticism Reader. (pp.15-36). Georgia: University of Georgia Press.

Gómez, E. (2016). El concepto de espacio en Martin Heidegger bajo su determinación en la noción de habitar como configuración de la obra arquitectónica. Instituto de filosofía. México: Tlaquepaque.

Turner, F. (1996). Cultivating the American Garden. The Ecocriticism Reader. (pp. 40-51) United States of America: University of Georgia Press.

Valero, C y Flys, C. (2010). Glosario básico bilingüe. Ecocríticas/Literatura y medio ambiente. (pp.371-377) Madrid: Iberoamericana/Vervuert. 